NBER WORKING PAPER SERIES

\title{
TAX EVASION AND THE ALLOCATION OF CAPITAL
}

\author{
Don Fullerton \\ Marios Karayannis
}

Working Paper No. 4581

\section{NATIONAL BUREAU OF ECONOMIC RESEARCH 1050 Massachusetts Avenue \\ Cambridge, MA 02138 \\ December, 1993}

\begin{abstract}
We are grateful for suggestions from Roger Gordon, Daniel Nagin, Ed Olsen, Christoph Schmidt, Jon Skinner, Steve Stern, Franz Van Winden, anonymous referees, and participants at the TransAtlantic Public Economics Seminar held June 1991 in Munich. We are also grateful for the extra efforts of Joel Stubbs at the IRS. This paper is part of the NBER's research program in Public Economics. Any opinions expressed are those of the authors and not those of the National Bureau of Economic Research.
\end{abstract}


NBER Working Paper \#4581

December 1993

TAX EVASION AND THE ALLOCATION OF CAPITAL

\begin{abstract}
The efficiency cost of capital misallocations between the corporate sector and the noncorporate sector is typically measured using statutory tax differences. Corporate-source income tax compliance is high because of third party reporting, however, while noncorporate rental income tax compliance is low. Differential evasion thus exacerbates statutory differences and enlarges the efficiency cost. To measure this effect, we build a numerical general equilibrium model where households simultaneously choose portfolios of risky assets and fractions of income to report.
\end{abstract}

Don Fullerton

Heinz School

Carnegie Mellon University

Pittsburgh, PA 15213

and NBER
Marios Karayannis

Price Waterhouse

Washington National Tax Service

Washington, DC 20006 


\section{Introduction}

A large body of economics literature studies the problem of tax evasion. Starting primarily with Allingham and Sandmo (1972), this literature considers the compliance decisions of households in the face of uncertainty. These households may receive exogenous income, or sometimes endogenous labor income, and they maximize expected utility given a probability and cost of detection. Government policy can affect these decisions by varying the tax rate, the audit rate, and the penalty on detected evasion. According to Internal Revenue Service (IRS) estimates, however, underreporting of income now costs the U.S. government 100 billion dollars a year, about 20 percent of income tax liability.

Most of this literature considers the evasion problem generally, or it concentrates on labor rather than capital income.' Yet the IRS (1988) estimates that more than half of the total loss in revenue is attributed to evasion of taxes on capital income.

A different large body of literature studies the problem of capital allocation. Starting primarily with Amold Harberger (1966), this literature considers the investment decisions of corporate and noncorporate firms facing different tax rules. Because the corporate sector must pay an additional layer of tax, it has a higher marginal effective tax rate and uses too little capital. With a fixed total stock of capital, the noncorporate sector uses too much. Estimates of the efficiency cost of such misallocation range around a half of one percent of national income. However, the marginal effective tax rates are based on the incentives of firms facing particular statutory provisions. The potential for tax evasion is ignored. ${ }^{2}$

Sandmo (1981) is an example. Cowell's (1990) book provides a collection of recent developments in the tax evasion literature. Yaniv (1990) models the choice of evasion between high-taxed capital income and low-taxed labor income, but he does not allow for the endogenous determination of these two income sources. Landskroner, Muller, and Swary (1991) consider a portfolio model with one riskless asset and one risky asset, where the evasion of labor income acts like investment in another risky asset.

2 Papers that use marginal effective tax rates to measure capital misallocations include Galper, Lucke and Toder (1988), Fullerton and Henderson (1989), and Gravelle (1989). 
Our paper attempts to bridge the gap between these two bodies of literature. The evasion of capital income is important not just because it may affect reported income and tax revenue. but because it may affect the amount of investment and its allocation. In this paper we concentrate on modifications to the standard Harberger analysis, that is, how evasion affects the allocation of a given stock of capital.

Evasion of capital income would not affect allocational efficiency if all assets were equally prone to evasion, but such symmetry seems unlikely. Strict reporting requirements now apply to banks and other intermediaries on their payments of interest and dividends, so evasion is difficult. In contrast, evasion may be easier on noncorporate capital income. A landlord may receive rents in cash, underreport that rental income, or overstate deductions for maintenance expenses. If the noncorporate sector already pays low effective tax under statutory provisions, then differential evasion exacerbates misallocations and enlarges efficiency costs.

To measure the potential size of these effects, we build a numerical general equilibrium model with two production sectors and with a household portfolio choice over one riskless and two risky financial assets. Only the risky noncorporate asset generates income that can be evaded. Households weigh their evasion opportunities, evaluate the relative attractiveness of assets, and determine their investment and consumption choices. A contribution here is that portfolio and evasion decisions are simultaneous. Households are aware of the subsequent compliance problem when setting the initial portfolio, and decide on a plan regarding tax compliance for each possible realization of the risky portfolio return. Thus capital allocation is influenced both by tax rules and by IRS imposed audit rates and penalties. Another important 
contribution is that the risky portfolio decision and the risky evasion decision are determined together using a single specification of risk aversion.

We first assume no evasion and simulate the removal of statutory tax differences among the three assets. The efficiency gain is 15.9 billion dollars per year, or .706 percent of national income, a figure comparable to those in the earlier Harberger literature that ignores evasion. Next, using IRS estimates, we assume that 20 percent of noncorporate capital income is evaded in the benchmark equilibrium. We then simulate the same removal of statutory tax differences and find an efficiency gain of 21.9 billion dollars. This measure of the efficiency cost of misallocations is made 37 percent larger by the consideration of evasion.

We also use the model to evaluate specific policies. Increased enforcement can improve allocational efficiency in our model, as well as raise revenue, but it is not costless. Additional auditing entails a specific resource cost, while penalties increase risk-bearing. In our model, an increase in either the audit rate or the penalty rate still yields a net welfare gain. Finally, the Tax Reform Act of 1986 may have affected evasion incentives by reducing personal marginal tax rates and by changing the relative taxation of different capital assets. We find that the efficiency gain from this reform is doubled when we account for effects on evasion.

\section{A Description of the Model}

Our portfolio model builds on previous models by Slemrod (1982 and 1983), Galper, Lucke, and Toder (1988), and Berkovec and Fullerton (1992). It includes bonds as a riskless asset, and corporate equity and real estate as two risky assets. To illustrate the effect of evasion on capital allocation, it is sufficient to have only one asset generate income that can be evaded. We take that asset to be real estate, since rental income is not subject to independent information reporting to the IRS. Thus we allow the underreported asset to interact with other fully reported 
assets, both riskless and risky. The inclusion of additional risky assets would complicate the investigation without adding any particular economic insights.

The reporting decision is described by a compliance model which extends and generalizes Allingham and Sandmo (1972). The basic model uses many identical consumers, all evading part of rental income, but a later section investigates the difficulties and the results of using multiple consumers at different income levels and tax brackets. The economy has two sectors, a corporate sector and a non-corporate rental housing sector. Owner-occupied housing is omitted. ${ }^{3}$ We assume perfect competition, full information, no externalities, perfect mobility, and full employment of labor and capital. Data on original portfolio allocations for the 1983 base year were obtained from the Survey of Consumer Finances by Berkovec and Fullerton (1992). This benchmark equilibrium is characterized by unequal effective tax treatment of different assets. Noncorporate income is subject only to personal income tax, whereas corporate income faces an additional corporate tax. When government changes a tax policy parameter, investors rearrange their portfolios and affect the aggregate supply of each asset. Relative prices adjust and capital reallocates between the two sectors, until equilibrium is achieved in factor markets as well as in product markets. An equivalent variation measures the dollar value to households of the combined changes in tax rates, evasion choices, resource allocation, the riskiness of income, and the consumption of each good.

2.1 Households. Each household faces uncertainty from two sources. First, evaded income is detected with probability $p$, and it escapes detection with probability (1-p). Second, real rates of return to corporate equity, $\mathrm{r}_{\mathrm{E}}{ }^{\circ}$, and to rental real estate, $\mathrm{r}_{\mathrm{R}}{ }^{\circ}$, are stochastic. The real

3 The non-corporate sector consists of rental housing only. We abstract from the detailed treatment of homeownership to concentrate on the choice between evadable real estate and non-evadable corporate-source income and to avoid the difficulty of distinguishing between consumption and investment characteristics of homeownership. 
return to debt, $r_{\mathbf{D}}{ }^{*}$, is not stochastic. These market returns (with asterisks) are used below to derive individual net-of-tax returns (with no asterisks). Then expected utility is

$$
E(V)=\int_{-\infty}^{+\infty} \int_{-\infty}^{+\infty}\left[(1-p) V\left(I_{n}\right)+p V\left(I_{d}\right)\right] f\left(r_{E}^{*}, r_{R}^{*}\right) d r_{E}^{*} d r_{R}^{*}
$$

where $\mathrm{V}($.$) is the indirect utility function, and \mathrm{f}($.$) is the probability distribution function of the$ returns. After-tax income is $I_{a}$ if evasion is not detected and $I_{d}$ if it is detected:

$$
\begin{aligned}
& I_{n}=Y+r_{D} A_{D}+r_{E} A_{E}+r_{R}^{*} A_{R}\left(1-t_{R} \delta\right) \\
& I_{d}=Y+r_{D} A_{D}+r_{E} A_{E}+r_{R}^{\dot{A}} A_{R}\left[1-t_{R}-\left(a t_{R}+\theta\right)(1-\delta)\right]
\end{aligned}
$$

Household income components include net asset income from debt $A_{D}$, corporate equity $A_{E}$, and real estate $A_{R}$, and other income $Y$ from after-tax labor earnings and government transfers (the wage rate is endogenous to the model, but fixed to the individual). The fraction of taxable rental income reported is $\delta$; the marginal tax rate on rental income is $t_{k}$; the proportional penalty on detected tax underpayment is a; and $\theta$ is a psychic cost parameter that generates disutility when evasion is detected. This non-monetary cost may include the embarrassment of being publicly exposed as a tax-cheater and the value of time lost in litigation. We assume this $\operatorname{cost} \theta$ is proportional to the income understatement. Successful evasion entails no such cost.

The probability of detection, $\mathrm{p}$, is modeled as a decreasing function of the reporting fraction $\delta$ (see, e.g. Klepper and Nagin, 1989). More specifically,

$$
p=\exp \left(a_{0}\left(a_{1}-\delta\right)\right)
$$

where $a_{0}$ and $a_{1}$ are parameters used to ensure that $p$ takes values in the $[0,1]$ interval. This feature of the model serves a dual purpose: first, it reflects the realistic result that, all things 


$$
-6-
$$

considered, additional evasion will increase the likelihood of an audit; ${ }^{4}$ second, it makes the overall enforcement effort and the administrative cost endogenous.

Consumers maximize a simple utility function, $\mathrm{U}=\gamma_{0} \mathrm{C}^{\gamma 1} \mathrm{H}^{\gamma 2}$, where $\mathrm{C}$ is the corporate good and $\mathrm{H}$ is housing. Substitution of demands back into utility yields indirect utility:

$$
V(I, P)=\frac{I^{\gamma_{1}+\gamma_{2}}}{\gamma_{1}+\gamma_{2}} \cdot \frac{1}{\bar{P}}
$$

where $\overline{\mathrm{P}}$ is the "ideal" price index, a function of prices and parameters. If the two exponents sum to one, as in the Cobb Douglas case, the individual is risk neutral. In general, however, the constant coefficient of relative risk aversion is $\beta \equiv 1-\gamma_{1}-\gamma_{2}$. In all cases below, we use $\beta>1$, so $\gamma_{1}$ and $\gamma_{2}$ are negative. As long as the scalar $\gamma_{0}$ in the utility function is also negative, then utility is still increasing in $\mathrm{C}$ and $\mathrm{H}$. Expenditures are still constant fractions of income, defined after portfolio realizations, evasion, detection, and penalities. Armed with these functional forms and parameter values, and facing a particular price vector, the consumer is prepared to maximize expected utility in equation (l) by choosing the reporting fraction $\delta$ and the asset vector $A=\left(A_{D}, A_{E}, A_{R}\right)$. Aggregate consumption demands for $C$ and $H$ are weighted averages of demands based on $I_{d}$ and demands based on $I_{n}$, using $p$ and (1-p) as weights.

2.2 Personal Taxation. Labor income is taxed according to a simple linear structure where the marginal tax rate is constant above $\mathrm{I}_{0}$. Each asset receives a separate treatment by the tax system in 1983. In the absence of evasion, the net-of-tax real rates of return are: where $\pi$ is the rate of inflation. For debt, the nominal interest rate is taxed at the investor's marginal rate on interest income $t_{D}$. Of the return to equity, net of corporate taxes, a fraction

4 We assume households know this probability function. They do not know whether they will be audited, only the likelihood of an audit for every level of compliance. 


$$
\begin{aligned}
& r_{D}=\left(r_{D}^{\dot{1}}+\pi\right)\left(1-t_{D}\right)-\pi \\
& r_{E}=\left(r_{E}^{\dot{1}}+\pi\right)\left[1-e t_{E}-(1-e) t_{G}\right]-\pi \\
& r_{R}=\left[\left(r_{R}^{\dot{1}}-m-t_{P}\right)\left(1-t_{R}\right)\right] /\left(1-t_{R} Z\right)-d
\end{aligned}
$$

e is distributed as dividends and taxed at personal rate $t_{E}$, while $(1-e)$ is retained and generates accrued capital gains that are taxed at the effective rate on accrued capital gains, $t_{G}$. The net return to real estate holdings is calculated as in Berkovec and Fullerton (1992) by taking into account maintenance expenses, $m$, property taxes, $t_{p}$, economic depreciation, $d$, and the present value of the tax savings from capital consumption allowances, $t_{R} Z$. These allowances are discounted at the individual's net nominal risk-free rate $\left(r_{D}^{*}+\pi\right)\left(1-t_{D}\right)$.

Owners of rental property report only a fraction $\delta$ of their true income $\left(r_{R}{ }^{-}-m-t_{p}\right)$. Letting the symbol $r_{R}{ }^{\prime}$ stand for $\left(r_{R}{ }^{*}-m-t_{p}\right) /\left(1-t_{R} Z\right)$, the net return becomes $r_{R}{ }^{\prime}\left(1-\delta t_{R}\right)-d$ if evasion is successful, and $r_{R}^{\prime}\left(1-t_{R}-(1-\delta)\left(a t_{R}+\theta\right)\right)-d$ otherwise.

Through taxation of stochastic asset income, government takes part of the variance as well as part of the returns. Assuming perfect loss offset, the tax on the variance would enhance individual welfare. However, the government cannot diversify better than fully-informed individual investors with access to national asset markets. Therefore the risk received by government does not "disappear," but must still somehow affect the welfare of individuals. For simplicity, we assume that this risk is returned in the form of a stochastic positive or negative lump-sum transfer. Individuals cannot affect the amount of this additional transfer from the government, but they recognize that it is correlated with the rates of return to their risky assets.

2.3 Production. The model includes two production sectors. The housing sector uses capital only, so one unit of housing capital produces one unit of housing services $H$. In the corporate sector, competitive firms produce $C$ using capital $K_{c}$ and labor $L$. Also, the firm is assumed to finance this capital with a fixed ratio of debt to equity, $b$. The demand for equity 
is then $E_{c}=K_{c} /(1+b)$, and the demand for debt is $D_{c}=K_{c}-E_{c}$. In order to measure the corporate cost of capital, $r_{s}$, we examine the separate tax treatment of equipment, structures, land, inventories, and intangibles. Following Hall and Jorgenson (1967),

$$
r_{c}=\left(r_{c}^{*}+d\right)(1-k-u Z) /(1-u)+t_{p}-d
$$

where $\mathrm{k}$ is the investment tax credit, $\mathrm{u}$ the corporate tax rate, $\mathrm{Z}$ the present value of capital consumption allowances, and $\mathrm{d}$ is the exponential rate of economic depreciation. The property tax rate $t_{p}$ and the parameters $d, k$, and $Z$ differ by asset. The firm's discount rate, $r_{c}{ }^{\circ}$, is a weighted average of the cost of debt and equity financing:

$$
r_{c}^{*}=\frac{\left(r_{E}^{*}+\pi\right)+b\left(r_{D}^{*}+\pi\right)(1-u)}{(1+b)}-\pi
$$

This expression indicates that debt financing is favored by the deduction of interest payments from the firm's taxable income. We assume that the firm is taxed at the top corporate marginal tax rate and has sufficient liability to qualify for all available deductions and credits.

2.4 Government. In the raw data, observed household bond holdings exceed corporate bond issues, so we attribute the difference to government bond issues. Similarly, the difference between rental housing demand and rental housing holdings is attributed to government supply of rental housing. These amounts are held constant during any simulation.

Revenue accrues from individual taxes on income from labor and capital, from corporate income taxes, and from the return to rental property owned by government. Tax revenue from housing capital is equal to expected revenue from each of the two possible outcomes of detection, weighted by the probabilities of occurrence. 
Government spending consists of a lump-sum transfer to consumers which is held fixed throughout, interest payments on its debt, and consumption of the corporate good which is also held fixed during the simulations. Part of tax revenue is spent on enforcement efforts as captured in an ad hoc administrative-cost function. Enforcement outlays rise with the square of $p$, while a fixed cost is incurred regardless of the frequency of audits. ${ }^{5}$

When a single tax provision changes in any of the experiments, government revenue will change. In order to maintain a balanced budget, a tax scalar is applied to all personal tax rates and the corporate rate, determined endogenously by the model in its search for an equilibrium. ${ }^{6}$

\section{Implementation, Data and Parameters}

As described, the model has no analytical solution. The general problem involves the entire joint density function of the two stochastic retums. Therefore we use numerical methods. We assume specific functional forms for the utility function (described above) and production function (constant elasticity of substitution). We also assume that the two stochastic returns are distributed joint normally, but we use the approximation given by the Hermite integration formula. We find sufficient accuracy using six realizations of each retum, so we evaluate utility at $6 \times 6=36$ realizations of the combined portfolio return.

5 A similar specification is used in Slemrod and Yitzhaki (1987).

6 In response to a tax policy change, the search for a new equilibrium iterates on a vector of six "prices" that includes the three expected rates of return $\left(r_{D}{ }^{*}, r_{E}{ }^{*}\right.$, and $r_{R}{ }^{*}$, the endogenous tax scalar for budget balance, and two endogenous scalars that indicate the amount of equity risk and the amount of real estate risk that are returned by government to households. These scalars are necessary because households need to know how much risk they will receive from the government before they choose portfolios, but the chosen portfolios affect the size of the stochastic transfers. 
The Hermite formula tells us which 36 points to evaluate, and the weight to attach to each point. Let $z_{i}$ and $v_{j}$ indicate the evaluation points for the two realizations of $r_{E}$ and $r_{R}$, with $i, j=1, \ldots, 6$. Tables in Stroud and Secrest (1966) tell us that the best approximation is achieved using points that are $.436,1.336$, and 2.351 standard deviations away from the mean in either direction. The best weights, $x_{i}$, are .725 for the point closest to the mean, in either direction, followed by .157 , and .0045 on the point furthest from the mean. These weights do not sum to one because they are not "probabilities" for the particular realizations. Instead, these values were derived for the tables by a numerical search for whatever $(z, v, x)$ combination happens to provide the best possible approximation for the joint normal distribution.

The household selects its portfolio, and it plans a reporting fraction for each possible realization of the portfolio return. Hence it must choose a vector of three assets, $\mathbf{A}$, and a vector of 36 reporting fractions, $\delta$, to maximize final expected utility. With the use of the Hermite formula, the consumer's optimization problem becomes

$$
\max _{A, \delta} E(U)=\sum_{i=1}^{6} x_{i} \sum_{j=1}^{6} x_{j}\left[(1-p) V\left[I_{n}\left(A, \delta ; z_{i}, v_{j}\right)\right]+p V\left[I_{d}\left(A, \delta ; z_{i}, v_{j}\right)\right]\right]
$$

subject to $A_{D}+A_{E}+A_{R}=K$, the fixed household capital. The consumer still realizes income $I_{d}$ after detection, with probability $p$, and income $I_{n}$ with probability $(1-p)$. But these income amounts are each now a function of the chosen asset vector $\mathbf{A}$ and reporting fractions $\boldsymbol{\delta}$, for each of the 36 realizations $\left(z_{i}, v_{j}\right.$, for $\left.i, j,=1,6\right)$. The Appendix uses the Hermite integration formula to derive explicit expressions for these functions, as used in the simulations.

A simultaneity problem is that the portfolio cannot be determined until the whole set of $\delta$ is derived, but these reporting fractions cannot be determined until total income is known. To solve this problem, we start with an initial guess for $\mathbf{A}$ and then iterate to find the optimal $\delta$ for 
each of the 36 outcomes. Armed with these reporting fractions, we use Newton's Algorithm to revise the initial setting of $\mathbf{A}$. We iterate between these two sub-problems to find a simultaneous solution for $\mathbf{A}$ and $\delta$. This solution captures the interactions between asset risk and evasion risk within a single optimization. The entire solution must be repeated, however, for each trial price vector along the search for a general equilibrium.

Next, we need to set the initial fractions of income reported in each sector. These are crucial for our model, but difficult to define and to measure. At large corporations, accountants work year-round with IRS auditors to negotiate appropriate tax amounts. Initial reporting may be low, but settlements avoid high penalties. More appropriate for our model are the amounts that individuals report. Fortunately, the IRS was able to compute for us the fraction reported of each income type, as shown in Table $1 .^{7}$ Because of third-party reporting, IRS computers can match individual tax returns with brokers' statements regarding corporate-source interest, dividends, and capital gains. In Table 1, however, these categories include income originating in both sectors. The table shows 92 percent reporting for "capital gains" which are mostly corporate stock, and 61 percent reporting for Form 4797 gains from the sale of business property. Most noncorporate income appears on Schedule $\mathrm{C}$ with 75 percent reporting, or rents and royalties with 85 percent reporting. The bottom of the table combines six mostly-corporate categories ( 96 percent reporting) and four mostly-noncorporate categories (76 percent reporting). The difference is important for our purposes, so we use .8 for $\delta$.

For the rest of the model, the 1983 Survey of Consumer Finances contains detailed information on end-of-year household assets, sources of earnings, and consumption expenditures.

7 These numbers pertain only to understatements by those who file tax returns. Evidence in IRS (1988) suggests that about a quarter of the rental income received by nonfilers should have been reported. The $\$ 100$ billion tax gap mentioned in our introduction includes both filers and nonfilers. 
Berkovec and Fullerton (1992) extract the data from the survey, aggregate the many asset types into the three used here, and categorize households into eight income groups. We use sample weights from the survey to aggregate up to a single representative household.

In order to derive the marginal tax rates applicable to each type of asset income $\left(t_{\mathrm{b}}, t_{\mathrm{f}}\right.$, and $t_{\mathfrak{Q}}$, the eight household rates are weighted by holdings of each asset and the survey weights. The capital gains rate is 20 percent of the tax rate on dividends, to capture the 60 percent exclusion, the advantage of deferral, and the step-up of basis at death. The complete set of parameters used in our model is displayed in Table 1.

The real retum to debt, $\mathrm{r}_{\mathrm{D}}{ }^{\circ}$, is set at 0.05 in the benchmark equilibrium, and the nominal interest rate is ten percent. The real return to equity is $\mathrm{r}_{\mathrm{E}}{ }^{-}=0.12$, and the real return to real estate is $r_{\mathbf{R}}{ }^{*}=0.11$. When underreported rental income remains undetected the real net return to real estate is .0639 , but when evasion is detected it falls to 0.0032 because of the penalty and the psychic cost (see the paragraph that starts after equation 4).

The coefficient of relative risk aversion, $\beta$, is set at 2 for the standard case. This value conforms with estimates found in the literature (e.g. Friend and Blume, 1975), but we vary it for sensitivity analysis. The variance of the return to each risky asset is then calibrated so that the asset holdings reported in the survey are optimal, given the derived after-tax real rates of retum, the specified risk aversion, and other data. These values also appear in Table 1. Observed expenditures are then used to solve for $\gamma_{1}$ and $\gamma_{2}{ }^{8}$

A An additional complication is that tax revenue from asset income depends on all of the tax evasion parameters. Most of these are set exogenously, but the psychic cost parameter $\theta$ must be derived such that the taxpayer finds it optimal to report 80 percent of rental income in the benchmark equilibrium, given all other taxes, audit rates, and penalties, and given the intercept of the linear tax schedule. A simple iterative procedure derives values simultaneously for the psychic cost and the tax intercept. In the end, the linear tax system takes the form $-3,591+0.329 \mathrm{~L}$, and $\theta$ becomes 2.14 . 
Although penalties on detected evasion can vary, imposed fines in the U.S. are typically one-half of the tax underpayment. Thus we set a to one-half. We set the parameters of the probability of detection function so that the benchmark $\mathrm{p}$ falls in the reasonable range of 5 to 10 percent. Specifically, we assume that in the absence of evasion the IRS would audit 5.0 percent for prevention purposes, but when all rental income is evaded the probability of detection rises to 90 percent. These figures provide particular values for $a_{0}$ and $a_{1}$, and they imply that the audit rate for 20 percent evasion is $p=0.089 .9$

Turning to the production side, we solve for the capital share parameter that makes the observed use of factors equal to desired use of factors. The elasticity of substitution between capital and labor is set at 1.0 for the base case, but it is varied for sensitivity analysis. Zero profits implies that sales revenue equals factor cost, so solving for the scale parameter implies $\phi=1.051$. Rates of economic depreciation are taken from Hulten and Wykoff (1981), while other parameters for the five corporate assets are taken from Fullerton and Lyon (1988).

\section{Results}

We begin with the welfare cost of tax differences as it is calculated in previous literature. In a benchmark equilibrium with no tax evasion, housing capital is effectively taxed at a 39.0 percent rate. ${ }^{10}$ Because of two layers of tax on corporate-source income, the overall effective

9 Since the household must know income before reporting, the value of $\delta$ depends on the realization of the portfolio return. Thus $\delta$ is set to 0.8 whenever the mean return is realized, but differs at each of the 36 points of the Hermite formula.

10 The return pre-tax but net of maintenance and depreciation is $0.09(=0.11-0.01-0.01)$ and the net return as derived by equation (4) is 0.0549 . Thus the effective tax rate incorporates the effects of both personal and property taxes on rental housing. 
tax on corporate capital is 52.6 percent. "When these taxes on capital are equalized, to collect the same revenue, the common tax rate becomes 49.9 percent. We use this conceptual experiment to measure the welfare cost of tax differences. Although not a realistic policy proposal, it is equivalent to a reform that integrates corporate and personal tax systems and applies the full 49.9 percent rate to real interest, dividends, and accrued capital gains.

Table 3 shows first, in column 1, the benchmark equilibrium values for asset holdings. market returns, net retums, and compliance variables. Then in column 2 it shows the corresponding post-adjustment values for comparison. Tax equalization induces a portfolio reallocation away from real estate towards debt and equity, with a net 8.8 percent decrease in real estate holdings. The net return to equity rises, while the net return to real estate falls.

As shown at the bottom of the column, overall welfare increases by 15.9 billion in 1983 dollars. This figure corresponds to 0.706 percent of National Income, well within the range of previous estimates from models that ignore evasion.

Next we begin from a benchmark that includes tax evasion, in column 3 . Initial allocations are the same as in column 1 , but the net return $r_{R}$ is higher. We then conduct the same experiment. Households respond in a similar manner, in column 4 , but housing capital decreases by 7.6 percent. Because of the higher tax on real estate, compliance deteriorates. Still, however, welfare rises by $\$ 21.9$ billion, or 0.968 percent of National Income. Thus the efficiency cost of statutory tax differences is 37 percent larger than when measured in the previous type of model that ignores tax evasion.

$"$ Using equation (5), the gross return to corporate capital is 0.1137 . Using (4), the weighted average of net returns to corporate debt and equity is 0.0539 . The percentage difference is an effective tax rate that combines effects of personal, corporate, and property taxes. It is not much higher than the statutory rate on corporate income, because of credits and deductions such as for nominal interest payments. 
Tax evasion exacerbates preexisting distortions by reducing further the low effective taxation of housing capital. With evasion in the benchmark, the effective tax rate is 35.0 percent instead of 39.0 percent. This influence of evasion on tax distortions has not previously been explicitly recognized and measured.

The table also presents equilibrium prices. During both conceptual experiments, the real pre-tax rate of return to real estate increases while the post-tax return falls. Also, both the real pre-tax and post-tax rates of return to equity rise. Since the tax equalization experiments are designed to be revenue neutral, the tax scalar falls slightly to return the additional revenue. The cost of corporate capital $r_{c}$ decreases, causing capital to flow into the corporate sector.

Next, Table 3 also shows results of policy experiments. Just as current policy fails to minimize the efficiency cost of capital misallocations, it also may fail to use optimal enforcement strategies. The penalty rate is increased from 0.5 to 0.6 in column 5 , where portfolios change little, but the annual welfare gain is $\$ 150$ million. This net figure balances the gain from real resource allocation, as in a standard Harberger model, plus the gain from slightly reduced marginal tax rates, against the loss in utility from a higher penalty and increased riskiness of the reporting decision. Compliance improves by a mere four-tenths of one percent, raising the reporting fraction to 0.8032 . Evasion in this model is deterred both by the IRS penalty and by $\theta$, the psychic cost of detection. This policy experiment changes only the IRS penaliy, not the psychic cost, so the percentage change in total deterrence is smaller than the percentage change in the IRS penalty. ${ }^{12}$ Because effects on compliance and portfolio composition are small, equilibrium prices do not change measurably.

12 In Becker's (1968) model, with risk-neutral taxpayers, the government can save audit costs and raise penalties without limit. Polinsky and Shavell (1979) point out that the optimal penalty should be lower with risk averse agents and imperfect detection, in order to account properly for the risk facing these agents. Yitzhaki (1987) notes that "[e]ven if the penalty rate is as high as 400 percent, the probability of detection would have to exceed 0.2 in order for evasion to be prevented." 
As an alternative means of reducing tax cheating, in column 6 , the IRS can change the frequency of audits. In this model, however, the probability of detection, p, is a function of the reporting fraction, $\delta$. Therefore we change both parameters $a_{0}$ and $a_{1}$ of the probability function, equation (2), such that taxpayers are audited with 6 percent frequency rather than the previous 5 percent when all rental income is truthfully reported. Since the relationship between $\delta$ and $\mathrm{p}$ is monotonic, this change represents a shift in the audit function. ${ }^{13}$ At the initial level of compliance (i.e., 80 percent), the probability of detection increases from 0.089 to 0.107 . Then in the simulation, when households respond to the higher audit function by reducing tax evasion, the endogenous probability of detection decreases slightly to 0.0961 .

In the final equilibrium, voluntary reporting increases from 80 percent to 82.6 percent. The equilibrium expected net return to the evaded asset falls from 0.0585 to 0.0581 , which causes a portfolio reallocation of 0.43 percent of real estate capital. The net change in welfare is $\$ 382$ million, or 0.017 percent of National Income. In this general model, two effects work in each direction. Consumer utility is reduced in a direct sense by the greater chance of audit, and in an indirect sense by the administrative cost of the additional IRS audits. This cost, which is a pure loss to society, increases by $\$ 466$ million in this simulation. As a result, total enforcement cost rises from 1.0 percent to 1.08 percent of government revenue. In the other direction, the higher value of $p$ reduces the size of the evasion gamble for risk-averse taxpayers. Finally, in addition, the higher level of compliance helps to reduce the efficiency cost of capital misallocation in this model. The net gain is the $\$ 382$ million.

13 Another effective deterrent to non-compliance is third party reporting, like the 1099 forms (see Witte and Woodbury, 1983). Although our model cannot explicitly accommodate changes in independent information gathering by the IRS, results would be similar to those here for an increase in the probability of detection. 
$-17-$

Next we turn to marginal tax rates. In this model, a uniform reduction in marginal tax rates will reduce evasion of rental income taxes and thereby improve the efficiency of capital allocation. We measure the responsiveness of compliance in our model to a ten percent cut in personal tax rates, but with no change in equilibrium prices. Reporting increases from 80 percent to 81.33 percent of rental income, so the elasticity of evasion with respect to the tax rate is 0.657 . This figure is well within the range of Clotfelter (1983) who finds that a ten percent tax cut will reduce evasion by anywhere between 5.0 and 8.94 percent.

For effects of actual rate reduction on evasion, we consider the Tax Reform Act of 1986 (TRA86). This Act lowered tax rates but broadened the taxable base so as to keep revenue approximately the same. The capital gains exclusion and the investment tax credit were repealed, and the corporate tax rate was decreased from 46 to 34 percent. The Act increased depreciation lifetimes but altered the depreciation methods. All of these changes are incorporated in our model..$^{14}$

Column 7 of Table 3 reports equilibrium responses to the total package of reforms. In particular, the reported fraction of taxable rental income rises from 80 percent to 87 percent. This change in $\delta$ is not due solely to the decrease in marginal tax rates, but also to the decrease in the endogenous audit rate, the change in household income, and effects on all real rates of return. TRA86 increases welfare by $\$ 7.2$ billion per year, or .320 percent of National

i4 For personal rate reduction, we use estimates in Berkovec and Fullerton (1992). Weighted by type of income, the rate on labor income decreases from 0.329 to 0.232 , the rate for debt decreases from 0.350 to 0.238 , the rate for equity decreases from 0.481 to 0.271 , the capital gains exclusion is repealed, and the rate for real estate decreases from 0.411 to 0.260 . To represent the broadening of the tax base, we decrease the income exclusion so as to keep constant total revenue. 
Income. ${ }^{15}$ These gains arise from the reallocation in resources induced by the changes in the effective taxation of capital in each sector, and from the changes in compliance. Lower tax rates induce investors to report a higher fraction of their rental income, which reduces detection uncertainty and lowers the resource cost of IRS audits.

The repeal of the investment tax credit raises the cost of equipment, but the cuts in corporate and personal tax rates reduce the overall effective tax on corporate capital from 52.6 to 42.3 percent. In the housing sector, the lower personal tax rate on rent is partially of tset by the slower depreciation of structures and by higher reporting of rental income. The effective tax on housing capital falls only from 39.0 percent to 34.6 percent. Therefore TRA 86 makes investing in the corporate sector relatively more attractive than it was before. It reduces the disparities in the taxation of capital across sectors.

Finally, we test the misspecification in previous studies that ignore tax evasion. If we start with a benchmark without evasion and simulate the effects of TRA86, then welfare increases by $\$ 3.6$ billion annually (.16 percent of National Income). This gain derives primarily from the Act's reduction of tax disparities across sectors. Yet, in our model with tax evasion, the same reform raises welfare by $\$ 7.2$ billion annually ( .32 percent of National Income). Thus the efficiency gain from tax reform is doubled by the consideration of tax evasion.

\section{Sensitivity and Extensions}

We now vary some key assumptions in our model. First, the standard model uses 0.8 for the initial noncorporate reporting fraction, $\delta$, and 2.0 for the coefficient of relative risk

15 In comparison, Gravelle (1989) finds that the tax reform increased welfare by 0.86 percent of consumption, and Fullerton and Mackie (1989) find gains about 0.35 percent of total welfare (the present value of income and the value of leisure). 
aversion, $\beta$. These parameter values are varied in Table 4. If the initial reporting fraction were only 0.7 , then welfare gains would be larger for equalizing tax rates, for increasing the penalty or audit rate, or for TRA86. Increases in $\delta$ reduce those gains. If $\delta$ were 0.9 , the higher audit rate entails more administrative cost than efficiency gain. In contrast, varying the degree of risk aversion has little effect on tax distortions. Tax equalization does not change the total riskiness of household portfolios, because part of low-risk real estate holding is converted to high-risk corporate equity. This table shows calculations for $\beta=6$ in this identical-consumer model, to compare later with calculations for $\beta=6$ in the multiple-consumer model. In other tests, we found that results were not sensitive to: the elasticity of substitution in production $(\sigma)$, the slope of the probability function ( $a_{1}$ relative to $a_{0}$ in equation 2 ), and an "open economy" assumption with a fixed world interest rate (see our 1992 working paper).

We turn now to a different extension of the basic model. Instead of many identical households, eight different groups are distinguished by the level of total income. These eight consumers face different marginal tax rates, supply different amounts of labor, and own progressively larger amounts of capital. All households hold all assets (see Berkovec and Fullerton, 1992). All evade twenty percent of their rental income, and they all face the same probability of detection. The relevant household-specific parameters for this model are derived exactly as in the base model. We also derive sixteen multiplicative parameters (one for each risky asset for each household) that modify the "perceived" riskiness of each asset, in such a way that the desired asset holdings in the benchmark are the same as observed holdings in the data set. Finally, for the model to solve, the coefficient of relative risk aversion for all eight households must be set to $6 .^{16}$

16 We raise $\beta$ from 2 to 6 to insure that total income is always positive for every group, as required to evaluate our utility function. Expected income is always positive, when $\beta$ is 2.0 , but some of the 36 evaluation points include large negative returns to equity and real estate. In addition, Friend and Hasbrouck (1980) found empirical support for the 
Our 1992 working paper includes results from all experiments using the eight-consumer model, but in Table 5 we report results only from the change in penalties and audit rates. The effects for the middle-income household in the eight-consumer model in Table 5 are similar to those for the one-consumer model with the same risk aversion parameter in Table 4 .

Although these changes in enforcement policies have small aggregate effects, they have interesting distributional effects. When we increase the penalty, as a fraction of the unpaid tax, high-bracket households have more incentive to comply and to reduce their rental housing investment. A higher audit affects all brackets similarly, and it has more effect on reporting. In both cases, households in the top three income brackets shift out of real estate. The resulting increase in the gross return to real estate restores its attractiveness for low-bracket households.

The middle classes reap the benefits from the improved allocation of resources, while the households in the top and bottom brackets become worse-off. More frequent audits inflict substantial losses on the wealthiest taxpayers, primarily due to income effects. Nevertheless, the sum of gains exceeds the losses. These results are consistent with the findings of the single household formulation of the model.

\section{Conclusion}

We use a general equilibrium simulation model to show how tax evasion can exacerbate tax differences across sectors. By underreporting income from the least-taxed asset, households exacerbate misallocation of capital and increase the economic inefficiency of the 1983 tax structure by 37 percent. Existing measures of tax distortions that ignore evasion are misspecified and substantially underestimate the efficiency cost of capital taxation.

higher value of the coefficient of relative risk aversion. 
We also show that attempts by the IRS to curb non-compliance, either by auditing a larger number of returns or by imposing higher penalties, can affect both the reporting and the investment decisions of households. We use the model to gauge the impact of the 1986 Tax Reform Act. The reduction in marginal tax rates induces higher levels of compliance, which adds to the welfare gains. Other models miss the effect of compliance on capital allocation and, consequently, they underestimate the effect of TRA86 on economic efficiency. Thus effects of tax evasion are not limited to individual evaders and leakage of revenue. Tax evasion can affect household investment decisions, equilibrium prices, and the allocation of capital. 


\section{Appendix}

Assets $A_{E}$ and $A_{R}$ have stochastic returns, while asset $A_{D}$ is riskless. Let

$$
\begin{aligned}
& u_{E}=r_{E}-\mu_{E} \\
& u_{R}=r_{R}-\mu_{R}
\end{aligned}
$$

where $\mu_{E}$ and $\mu_{R}$ are the mean returns on the two assets, and $u_{E}$ and $u_{R}$ are distributed $N(0, \Omega)$. Let $\sigma_{\mathrm{E}}$ and $\sigma_{\mathrm{R}}$ be the standard deviations of each stochastic return, and $\omega$ be the correlation coefficient. The next step is to express expected utility in terms of normally distributed variates with mean zero. This is necessary in order to apply the Hermite integration formula to each of the two integrals in the utility function.

The utility function from equation (1) can now be expressed in terms of $u$ as:

$$
E(V)=\int_{-\infty}^{+\infty} \int\left[(1-p) V\left(I_{n}\right)+p V\left(I_{d}\right)\right] f\left(u_{E} u_{R}\right) d u_{E} d u_{R}
$$

where

$$
\begin{aligned}
& \mathrm{I}_{\mathrm{n}}=\bar{I}_{n}+\mathrm{u}_{\mathrm{E}} \mathrm{A}_{\mathrm{E}}+\mathrm{u}_{\mathrm{R}} \mathrm{A}_{\mathrm{R}}(1-\mathrm{t} \delta) \\
& \mathrm{I}_{\mathrm{d}}=\bar{I}_{d}+\mathrm{u}_{\mathrm{E}} \mathrm{A}_{\mathrm{E}}+\mathrm{u}_{\mathrm{R}} \mathrm{A}_{\mathrm{R}}[1-\mathrm{t}-(\mathrm{at}+\theta)(1-\delta)],
\end{aligned}
$$

where $\bar{I}_{n}$ and $\bar{I}_{d}$ indicate total expected income in each case, and where 


$$
f\left(u_{E} u_{R}\right)=\frac{2 \pi}{\sqrt{\sigma_{E}^{2} \sigma_{R}^{2}\left(1-\omega^{2}\right)}} \exp \left\{-\frac{1}{2\left(1-\omega^{2}\right)}\left[\frac{u_{E}^{2}}{\sigma_{E}^{2}}+\frac{u_{R}^{2}}{\sigma_{R}^{2}}-\frac{2 \omega u_{E} u_{R}}{\sigma_{E} \sigma_{R}}\right]\right\}
$$

We decompose the joint density into the product of the conditional and marginal densities, and rewrite (A1) as

$$
E(V)=\int_{-\infty}^{+-}\left\{\int_{-\infty}^{+\infty}\left[(1-p) V\left(I_{n}\right)+p V\left(I_{d}\right)\right] f\left(u_{E} \mid u_{R}\right) d u_{E}\right\} f\left(u_{R}\right) d u_{R}
$$

where

$$
f\left(u_{E} \mid u_{R}\right)=\left[2 \pi \sigma_{E}^{2}\left(1-\omega^{2}\right)\right]^{-\frac{1}{2}} \exp \left[-\frac{\left(u_{E}-\omega \frac{\sigma_{E}}{\sigma_{R}} u_{R}\right)^{2}}{2 \sigma_{E}^{2}\left(1-\omega^{2}\right)}\right]
$$

is the conditional p.d.f., and

$$
f\left(u_{R}\right)=\left(2 \pi \sigma_{R}^{2}\right)^{-\frac{1}{2}} \exp \left(-\frac{u_{R}^{2}}{2 \sigma_{R}^{2}}\right)
$$

is the marginal p.d.f. Next we use the change of variable technique to transform the inner integral of (A2), in order to express the function in terms of the variable $z$. Recall that $z$ times $\sigma_{E}$ is the distance of the evaluation point from the mean. Let

$$
z=\frac{u_{E}-u_{R} \omega \frac{\sigma_{E}}{\sigma_{R}}}{\sqrt{2\left(1-\omega^{2}\right)} \sigma_{E}}
$$

Solving for $u_{E}$ and taking the total differential gives the following solution for $\mathrm{du}_{\mathrm{r}}$. 


$$
d u_{E}=d z \sqrt{2\left(1-\omega^{2}\right)}
$$

Substituting $d u_{E}$ back into the utility function and the two constraints, we obtain:

$$
\left.\left.E(V)=\frac{1}{\sqrt{\pi}} \int_{-\infty}^{+\infty}\left\{\int_{-\infty}^{+\infty}\left[(1-p) \eta I_{n}(z)\right]+p \eta I_{d}(z)\right]\right] e^{-z^{2}} d z\right\} f\left(u_{R}\right) d u_{R}
$$

Using the Hermite integration formula, we replace the variable $z$ by its realization $z_{j}$, the term $\exp \left(-z^{2}\right)$ by the weights $x_{j}$, and sum over the 6 points, to obtain:

$$
\left.\left.E(V)=\frac{1}{\sqrt{\pi}} \int_{-\infty}^{+\infty}\left\{\sum_{j=1}^{6} x_{j}\left((1-p) \eta I_{n}\left(z_{j}\right)\right]+p h I_{d}\left(z_{j}\right)\right]\right\}\right\} f\left(u_{R}\right) d u_{R}
$$

We repeat the same procedure again by performing change of variables to transform $u_{R}$ in terms of $v$, and use the Hermite integration formula to derive the utility function that is maximized as equation (5) in the main text, where

$$
\begin{aligned}
& I_{n}=\bar{I}_{n}+\sqrt{2} A_{E} \sigma_{E}\left[v_{j} \omega+z_{i} \sqrt{1-\omega^{2}}\right]+A_{R} v_{j} \sqrt{2} \sigma_{R}(1-t \delta) \\
& I_{d}=\bar{I}_{d}+\sqrt{2} A_{E} \sigma_{E}\left[v_{j} \omega+z_{i} \sqrt{1-\omega^{2}}\right]+A_{R} v_{j} \sigma_{R} \sqrt{2}[1-t-(a t+\theta)(1-\delta)]
\end{aligned}
$$




\section{REFERENCES}

Allingham, Michael and Agnar Sandmo, 1972, Income tax evasion: A theoretical analysis, Journal of Public Economics 1, November, 323-338.

Becker, Gary S., 1968, Crime and punishment: An economic approach, Journal of Political Economy 76, 169-217.

Berkovec, James and Don Fullerton, 1992, A general equilibrium model of housing, taxes, and portfolio choice, Journal of Political Economy 100, April, 390-429.

Clotfelter, Charles, 1983, Tax evasion and tax rates: An analysis of individual returns," Review of Economics and Statistics 65, August, 363-373.

Cowell, Frank A., 1990, Cheating the government: the economics of evasion (MIT Press, Cambridge, MA).

Friend, I., and M.E. Blume, 1975, The demand for risky assets, American Economic Review 65, December, 900-922.

Friend, I., and J. Hasbrouck, 1980, Effect of inflation on the profitability and valuation of U.S. corporations, University of Pennsylvania, mimeo (Philadelphia).

Fullerton, Don and Yolanda K. Henderson, 1989, A disaggregate equilibrium model of the tax distortions among assets, sectors, and industries, International Economic Review 30, May, 391-415.

Fullerton, Don and Andrew Lyon, 1988, Tax neutrality and intangible capital, Tax Policy and the Economy 2 (MIT Press, Cambridge, MA).

Fullerton, Don and James Mackie, 1989, Economic efficiency in recent tax reform history: Policy reversals or consistent improvements?, National Tax Journal 42, March, 1-14.

Galper, Harvey, Robert Lucke and Eric Toder, 1988, A general equilibrium analysis of tax reform, in: H. J. Aaron, H. Galper, and J. A. Pechman, eds., Uneasy compromise: Problems of a hybrid income-consumption tax (Brookings Institution, Washington DC).

Gravelle, Jane, 1989, Differential taxation of capital income: Another look at the 1986 tax reform act, National Tax Journal 42, December, 441-464.

Hall, Robert E. and Dale W. Jorgenson, 1967, Tax policy and investment behavior, American Economic Review 57, 391-414.

Harberger, Amold C., 1966, Efficiency effects of taxes on income from capital, in: $M$. Krzyzaniak, ed., Effects of corporation income tax (Wayne State University Press, Detroit). 
Hulten, Charles R. and Frank C. Wykoff, 1981, The measurement of economic depreciation, in: C. R. Hulten, ed., Depreciation, inflation, and the taxation of income from capital (Urban Institute, Washington DC).

King, Mervyn and Don Fullerton, eds., 1984, The taxation of income from capital: A comparative study of the U.S., U.K., Sweden, and West Germany (University of Chicago Press, Chicago).

Klepper, Steven and Daniel Nagin, 1989, The anatomy of tax evasion, Journal of Law, Economics, and Organization 5, Spring, 1-24.

Landskroner, Yoram, Eitan Muller, and Itzhak Swary, 1991, Tax evasion and financial equilibrium, Journal of Economics and Business 43, 25-35.

Polinsky, Michael A. and Steven Shavell, 1979, The optimal tradeoff between the probability and magnitude of fines, American Economic Review 69, December, 880-91.

Sandmo, Agnar, 1981, Income tax evasion, labour supply and the equity-efficiency tradeoff, Journal of Public Economics 16, December, 265-288.

Slemrod, Joel, 1982, Tax effects on the allocation of capital among sectors and among individuals: A portfolio approach, Working Paper No. 951, National Bureau of Economic Research, August (Cambridge, MA).

Slemrod, Joel, 1983, A general equilibrium model of taxation with endogenous financial behavior, in: M. Feldstein, ed., Behavioral simulation methods in tax policy analysis (University of Chicago Press, Chicago).

Slemrod, Joel and Shlomo Yitzhaki, 1987. The optimal size of a tax collection agency, Scandinavian Journal of Economics 89, September, 183-92.

Stroud, A. and D. Secrest, 1966, Gaussian quadrature formulas (Prentice-Hall, Englewood Cliffs).

U.S. Internal Revenue Service, 1988, Income tax compliance research: Gross tax gap estimates and projections for 1973-1992, Publication 7285 (Washington DC).

Witte, Ann D. and Diane F. Woodbury, 1983, What we know about factors affecting compliance with the tax laws, in: P. Sawiki, ed., Income tax compliance research: A report to the ABA section on taxation (American Bar Association, Washington DC).

Yaniv, Gideon, 1990, Tax evasion under differential taxation, Journal of Public Economics 43, 327-337.

Yitzhaki, Shlomo, 1987, On the excess burden of tax evasion, Public Finance Quarterly 15, April, 123-137. 
Table 1

\begin{tabular}{|c|c|c|c|c|}
\hline \multicolumn{5}{|c|}{$\begin{array}{c}\text { INDIVIDUAL INCOME TAX COMPLIANCE RATES } \\
\text { BY TYPE OF INCOME, } 1988\end{array}$} \\
\hline \multirow{2}{*}{$\begin{array}{l}\text { Income Item } \\
\text { (1) }\end{array}$} & \multicolumn{2}{|c|}{ Corrected Amount } & \multirow{2}{*}{$\begin{array}{c}\text { Reported } \\
\text { Amount } \\
\text { (S million) } \\
\text { (4) }\end{array}$} & \multirow{2}{*}{$\begin{array}{c}\text { Reporting } \\
\text { Fraction (\%) } \\
(4) /(2)= \\
(5)\end{array}$} \\
\hline & $\begin{array}{l}\text { ( } \$ \text { million) } \\
(2)\end{array}$ & $\begin{array}{l}(\%) \\
(3)\end{array}$ & & \\
\hline Wages, Salaries, Tips & $2,241,898$ & 72.7 & $2,237,664$ & 99.8 \\
\hline Taxable Interest Income & 180.065 & 5.8 & 177,417 & 98.5 \\
\hline Dividend Income & 70,323 & 2.3 & 67,707 & 96.3 \\
\hline State and Local Tax Refunds & 10,934 & 0.4 & 10,843 & 99.2 \\
\hline Alimony Received & 2.428 & 0.1 & 2.289 & 94.3 \\
\hline Business Income (or Loss) Schedule C & 157,616 & 5.1 & 118,533 & 75.2 \\
\hline Capital Gain or Loss Schedule D & 157,772 & 5.1 & 145,636 & 92.3 \\
\hline Capital Gain Distributions & 980 & 0.0 & 900 & 91.8 \\
\hline $\begin{array}{l}\text { Other Gains (or Losses) } 1 \text { ' } \\
\text { Form } 4797\end{array}$ & 4,528 & 0.1 & 2,753 & 60.8 \\
\hline Taxable IRA Distributions & 12,204 & 0.4 & 11,333 & 92.9 \\
\hline Taxable Pensions \& Annuities & 133,278 & 4.3 & 131,328 & 98.5 \\
\hline Rents, Royalties, other Schedule E & 80,610 & 2.6 & 68,458 & 84.9 \\
\hline Farm Income (or Loss) Schedule F & 3,224 & 0.1 & $-2,774$ & -86.0 \\
\hline Unemployment Compensation & 11,958 & 0.4 & 11.135 & 93.1 \\
\hline Taxable Social Security Benefit & 14,543 & 0.5 & 13,936 & 95.8 \\
\hline Other Income (or Loss) & 849 & 0.0 & $-12,607$ & -1484.9 \\
\hline Total Taxable Income & $3,083,210$ & 100.0 & $2,984,487$ & 96.8 \\
\hline Tax Exempt Income & 32,249 & n.a. & 31,635 & 98.1 \\
\hline Total Income & $3,115,459$ & n.a. & $3,016,122$ & 96.8 \\
\hline Total "Corporate" 21 & 554.622 & & 534,322 & 96.3 \\
\hline Total "Noncorporate" 3 / & 245,978 & & 186,970 & 76.0 \\
\hline $\begin{array}{l}\text { Total "Corporate" } \\
\text { excluding pensions and IRA's }\end{array}$ & 409,140 & & 391,660 & 95.7 \\
\hline
\end{tabular}

Notes:

1/ Consists of gains or losses incurred in the sale of business property.

2/ Includes taxable interest, dividends, capital gains, capital gains distributions, taxable IRA distritiutions, and pensions and annuities.

3/ Includes business income (schedule C), other gains and losses (form 4797), rents and royalties (schedule E), and farm income (schedule F).

Source: IRS. We are grateful to Joel Stubbs of the IRS for running these tabulations from the 1988 tape of the Taxpayer Compliance Measurement Program (TCMP). 
Table 2

\begin{tabular}{|c|c|c|}
\hline \multicolumn{3}{|c|}{ PARAMETERS } \\
\hline Symbol & Description & Value \\
\hline \multicolumn{3}{|c|}{ A. Estimated Elsewhere } \\
\hline 1 & tax rate on labor income & 0.329 \\
\hline$t_{D}$ & tax rate on debt (interest income) & 0.350 \\
\hline$t_{E}$ & tax rate on equity income & 0.458 \\
\hline$t_{R}$ & tax rate on real estate income & 0.411 \\
\hline$t_{p}$ & property tax rate on real estate & 0.018 \\
\hline u & corporate tax rate in 1983 & 0.46 \\
\hline d & economic depreciation rate & 0.01 \\
\hline$b$ & debt/equity ratio & 0.5 \\
\hline $\mathrm{e}$ & fraction of equity retained & 0.5 \\
\hline \multicolumn{3}{|c|}{ B. Chosen for this model } \\
\hline$r_{D} \cdot$ & real return to debt & 0.05 \\
\hline$r_{\mathrm{E}}^{\cdot}$ & real return to equity & 0.12 \\
\hline$r_{R} \cdot$ & real rental rate & 0.11 \\
\hline$\omega$ & correlation coefficient & 0.084 \\
\hline $\mathrm{m}$ & maintenance rate & 0.01 \\
\hline$\pi$ & inflation rate & 0.05 \\
\hline$\sigma$ & elasticity of substitution in production & 1.0 \\
\hline$\hat{o}$ & reporting fraction & 0.8 \\
\hline$\beta$ & coefficient of risk aversion & 2.0 \\
\hline a & rate of penalty on tax underpayment & 0.5 \\
\hline \multicolumn{3}{|c|}{ C. Calculated here } \\
\hline$r_{\mathrm{c}}$ & cost of capital & 0.1137 \\
\hline$\rho$ & capital share in production & 0.0983 \\
\hline$\phi$ & scale parameter in production & 1.051 \\
\hline $\mathrm{p}$ & probability of detection & 0.089 \\
\hline$\theta$ & psychic cost & 2.14 \\
\hline$s_{\mathrm{F}}$ & standard deviation of equity & 0.1945 \\
\hline$s_{R}$ & standard deviation of real estate & 0.1644 \\
\hline
\end{tabular}

Source: Tax rates are from Berkovec and Fullerton (1992), except for the property tax rate from King and Fullerton (1984). The debt/equity and retention ratios are also from King and Fullerton (1984). The reporting fraction is from IRS data in Table 1, and risk aversion estimates appear in Friend and Blume (1975) and Friend and Hasbrouck (1980). The chosen parameters in Panel B match the parameters used by Berkovec and Fullerton (1992). 


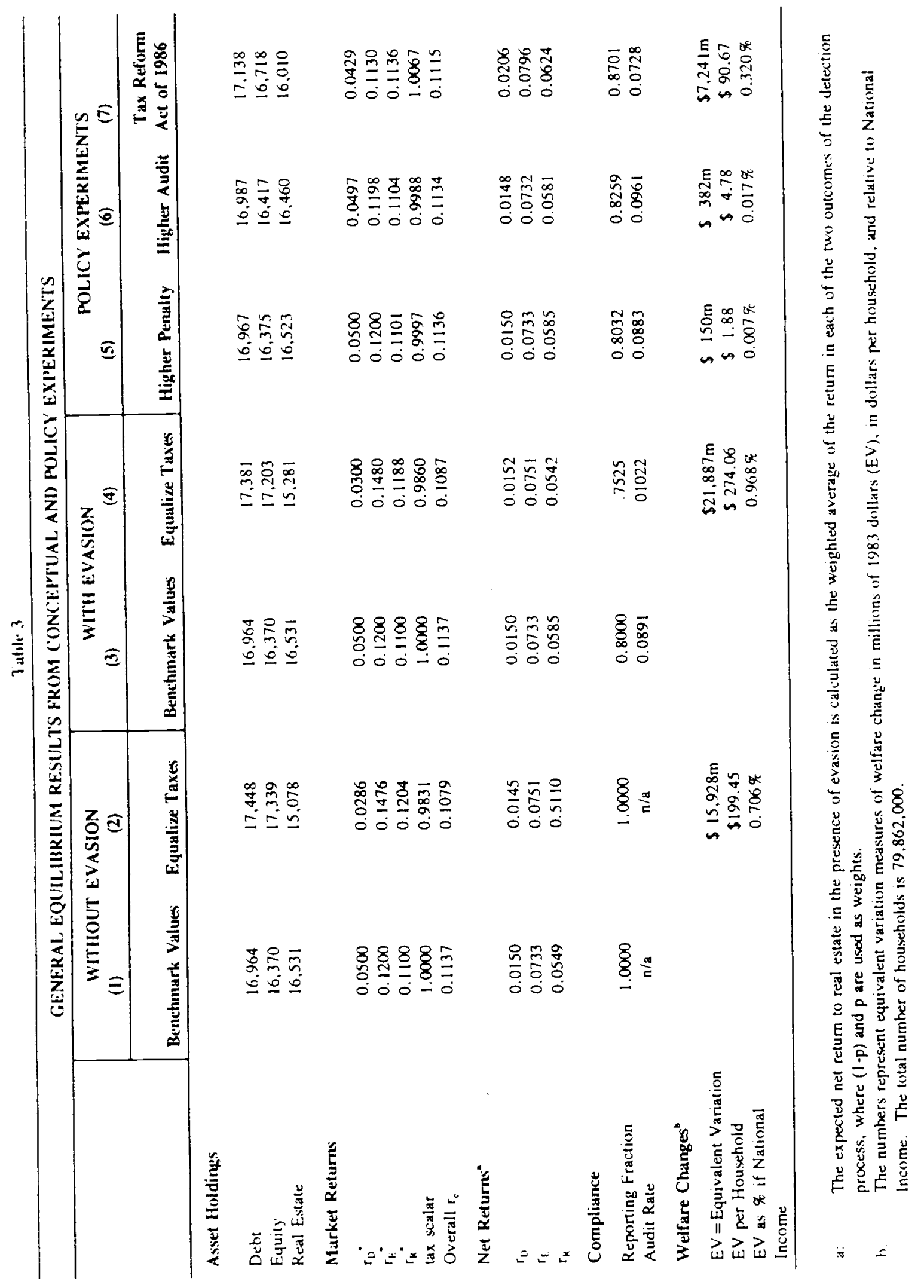


Table 4

\section{SENSITIVITY ANALYSIS}

equivalent variation as a percentage of National Income under alternative parameter values

(1)

Key Parameter Equalize

Values

with $\beta=2.0$,

and:

$\begin{array}{ll}\delta=0.7 & 1.042 \\ \delta=0.8 & 0.968 \\ \delta=0.9 & 0.874\end{array}$

(2)

Higher

Penalty
(3)

Higher

Audit
(4)

Tax Reform Act of 1986

with $\delta=0.8$, and

$\begin{array}{lllll}\beta=2.0 & 0.968 & 0.007 & 0.017 & 0.320 \\ \beta=3.0 & 0.953 & 0.007 & 0.016 & 0.320 \\ \beta=6.0 & 0.913 & 0.008 & 0.014 & 0.319\end{array}$

$\delta$ is the reporting fraction, and $\beta$ is the coefficient of risk aversion. 


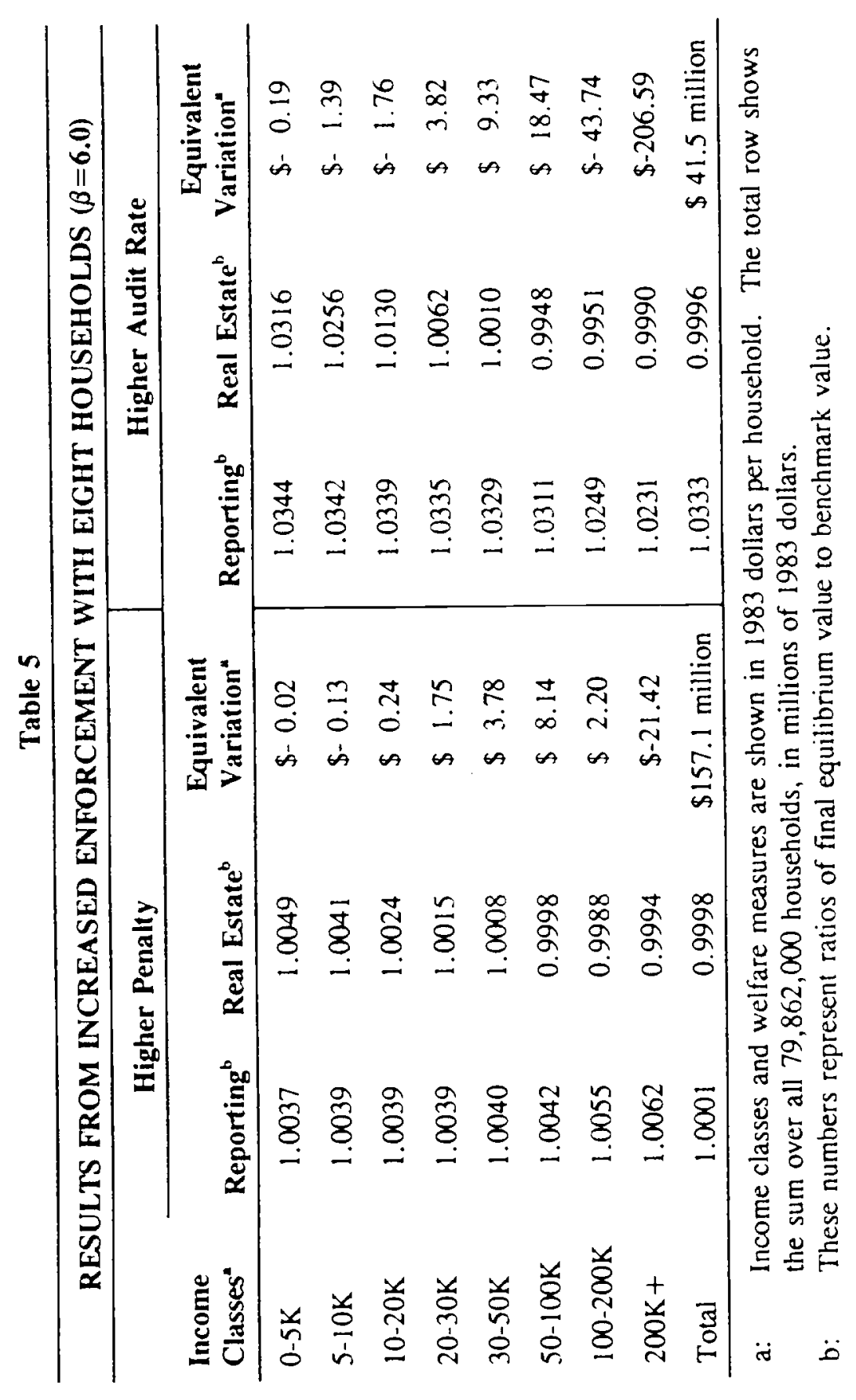

